\title{
San Antonio Review •
}

\section{Note from the Poetry Editor}

\section{Gianna Sannipoli ${ }^{1}$}

${ }^{1}$ San Antonio Review

Published on: Sep 07, 2021

License: Creative Commons Attribution 4.0 International License (CC-BY 4.0). 
"Can't I live in poems?"

— Leonard Cohen, “On the Sickness of My Love”

It has been an honor to read from all of the talented writers that contributed to $S A R$ for this issue, online and in print.

Us editors are immensely grateful for those of you that have read, supported, and submitted to San Antonio Review. We received a multitude of well-crafted submissions in all genres. The pieces in this issue reflect only a fraction of the incredible work that comes from $S A R$ 's contributors.

Beyond my gratitude for all of the artists and writers, I owe much to Will and Ash for their hard work, dedication, and patience. This publication would not be possible without their diligence and the support of those who read and submit to $S A R$. For many this year, art has been a form of solace. I hope that the poems featured in this issue serve as poems that readers can "live in," even if just for the duration of the reading.

Gianna Sannipoli studies poetry at Queens University in Belfast, Northern Ireland. She is San Antonio Review's poetry editor. 